\title{
The Effect of Long-Term HAART on the
} Incidence of Tuberculosis Among People Living
with HIV in Addis Ababa, Ethiopia: A Matched
Nested Case-Control Study

Ayinalem Alemu (iD) ${ }^{1,2}$ Zebenay Workneh Bitew (1D ${ }^{3}$ Aman Yesuf $\mathbb{D D}^{3}$ Betselot Zerihun' Melak Getu'

'Ethiopian Public Health Institute, Addis Ababa, Ethiopia; ${ }^{2}$ Aklilu Lemma Institute of Pathobiology, Addis Ababa University, Addis Ababa, Ethiopia; ${ }^{3}$ St. Paul's Hospital Millennium Medical College, Addis Ababa, Ethiopia
Correspondence: Ayinalem Alemu Tel +251912366676

Email ayinalemal@gmail.com
Background: The introduction of antiretroviral therapy (ART) significantly decreases the incidence of tuberculosis (TB) in people living with human immunodeficiency virus (PLWHIV). However, a considerable proportion is still co-infected with TB after ART initiation. Thus, this study aimed to assess the effect of long-term HAART on the incidence of TB among PLWHIV in Addis Ababa, Ethiopia.

Methods: A matched nested case-control study was conducted among PLWHIV who were enrolled in ART clinics in Addis Ababa, Ethiopia from 2013 up to 2018. Cases were HIV-TB co-infected individuals who were taking antiretroviral treatment, while controls were PLWHIV without TB who were taking antiretroviral treatment. The cases and controls are matched exactly in age and sex. Data were entered in Epi Info version 7.1 and analyzed using SPSS version 20. Bi-variable and multivariable conditional logistic regression were employed along with $95 \%$ CI. A P-value $<0.05$ in the multivariable analysis was considered statistically significant.

Results: Fifty-seven cases were compared with 114 controls. Accordingly, previous TB history $\left(\mathrm{X}^{2} ; 13.790, P<0.001\right)$, baseline functional status $\left(\mathrm{X}^{2} ; 9.120, P=0.010\right)$, baseline WHO clinical stage $\left(\mathrm{X}^{2} ; 10.083, P=0.001\right)$, baseline hemoglobin value $\left(\mathrm{X}^{2} ; 6.985, P=\right.$ $0.008)$, baseline body mass index $\left(\mathrm{X}^{2} ; 3.873, P=0.049\right)$, isoniazid preventive treatment $\left(\mathrm{X}^{2}\right.$; $8.047, P=0.005)$, baseline CD4 value $\left(\mathrm{X}^{2} ; 12.741, P<0.001\right)$ and length of stay on ART $\left(\mathrm{X}^{2} ; 53.359, P<0.001\right)$ were associated with developing TB. Length of stay on ART was found to be the statistically significant determinant of TB infection after ART initiation (aOR $=5.925,95 \% \mathrm{CI}=2.649-13.250)$.

Conclusion: Advanced clinical stages at the baseline, previous TB history, and not taking IPT were associated with TB infection. The long-term ART exposure significantly decreases tuberculosis incidence in PLWHIV. Thus, retaining PLWHIV on ART would be important to decrease the incidence of TB in this group of individuals.

Keywords: HAART, tuberculosis, long-term ART, matched nested case-control study

\section{Introduction}

Individuals infected with Human Immunodeficiency Virus (HIV) virus are vulnerable to secondary infections including tuberculosis (TB). ${ }^{1}$ Compared to the general population, the risk of TB infection is higher in people living with $\mathrm{HIV}^{2,3}$ such that people living with HIV have a $10 \%$ annual risk of TB infection. ${ }^{1}$ Based on the World Health Organization (WHO) estimates, people living with HIV are 19 times 
more likely to develop active TB disease than people without HIV. Besides, TB is the major cause of death in people living with HIV. ${ }^{4}$ Both TB and HIV are the major causes of morbidity and mortality globally. According to the 2019 global TB report, about 10 million individuals were infected with TB in $2018 .{ }^{5}$ In 2019 , among the total TB cases, $8.2 \%$ were HIV positive. ${ }^{6}$

Ethiopia is among the countries seriously affected by both infections. The 2021 global tuberculosis report showed that there were an estimated $132 \mathrm{~TB}$ cases per 100,000 population in Ethiopia. ${ }^{5}$ The country is among the TB, and TB/HIV high burden countries in the world., A recent study conducted in Ethiopia reported that $7.4 \%$ of TB patients are co-infected with HIV and $0.8 \%$ of people living with HIV are infected with active TB. ${ }^{7}$ Studies conducted in different settings reported that enrollment on highly active antiretroviral therapy (HAART) significantly decreases the incidence of TB infection such that those people living with HIV enrolled on HAART have a lower risk to develop tuberculosis compared to those not taking antiretroviral therapy (ART). ${ }^{8-12}$ Studies conducted in Ethiopia also supported this evidence. ${ }^{8,13-16}$ However, still considerable proportions of individuals who were enrolled in HAART develop TB in Ethiopia. ${ }^{17,18}$ Also, studies showed that the incidence of TB was higher in the early phase of ART initiation. ${ }^{19-23}$ Thus, we designed a matched nested case-control study where individuals are matched in age and sex to assess the effect of long-term HAART on the incidence of tuberculosis among people living with HIV.

\section{Methods}

\section{Study Setting and Period}

The study was conducted among seven ART centers found in Addis Ababa, the capital and the most urban city of Ethiopia. Patients who were enrolled in ART clinics from January to December 2013 were included in the study and were followed for five years up to December 2018 retrospectively. Data were collected retrospectively in a period between July and August 2019.

\section{Study Design}

A matched nested case-control study was conducted based on data collected in our previous retrospective cohort study published previously. ${ }^{13}$ For the current study, people living with HIV enrolled on HAART were selected based on their tuberculosis co-infection status, and the determinants were assessed retrospectively.

\section{Participants}

Based on the tuberculosis infection status, which is the outcome in the current study, people living with HIV who were taking ART were categorized into two groups, cases, and controls. Cases were HIV-TB co-infected individuals who were taking antiretroviral treatment, while controls were people living with HIV without TB who were taking antiretroviral treatment. Every case was matched with two controls exactly matched with age and sex. People living with HIV newly enrolled on HAART from 01 January 2013 to 31 December 2013 who were free from TB were included in the study and were followed retrospectively for five years up to 31 December 2018. Individuals who did not have baseline data and missed charts were excluded. All the people living with HIV in the current study were routinely screened for TB in their ART follow-up.

\section{Sampling Procedure}

Among a total of 566 people living with HIV included in our previous study, 476 individuals who were taking ART were selected in the first stage. Then, categorized into two groups, who developed TB and were not infected with TB in their follow-up period. HIV-TB co-infected individuals were categorized as cases and the counterparts were considered as controls. For every case, two controls with an exact match in age and sex were selected systematically. Accordingly, 57 cases were pair-matched with 114 controls. Thus, a total sample size of 171 was used in the study.

\section{Variables}

The dependent variable was tuberculosis infection and the independent variables were demographic characteristics (marital status, educational status, occupation, address, disclosure status, number of family members, and homeless), behavioral characteristics (smoking, alcohol use, Khat and substance use (Shisha)), baseline clinical characteristics (TB treatment history, functional status, WHO clinical stage, CD4 count, hemoglobin (Hgb) level, initial ART regimen type, isoniazid preventive treatment (IPT), co-infection other than TB and body mass index) and length of ART.

\section{Diagnostic Methods}

Tuberculosis diagnosis was based on Ethiopian tuberculosis and leprosy control guideline, ${ }^{24}$ such that TB is defined as any clinical, histological, and/or microbiological diagnosis. Microbiologically, different technologies are used to rule out TB. Among them, smear microscopy, 
mycobacterial culture, and Xpert MTB/RIF assay were used. Chest radiography, ultrasound, and pathological examination were also used to rule out TB. Besides, a clinician decision based on strong clinical evidence was also used. Among the 57 cases, 31 were diagnosed with extrapulmonary TB, while the remaining 26 were diagnosed with pulmonary TB. Several combinations of diagnostic methods were used to rule out TB. Accordingly, $24,23,8$, and 2 TB cases were confirmed by chest radiography, histological examination, microbiological diagnostic methods, and strong clinical evidence, respectively.

\section{Operational Definitions}

Cases: Cases were people living with HIV who developed tuberculosis infection during their ART follow-up.

Controls: Controls were people living with HIV who were not infected with tuberculosis during their ART follow-up.

Matching: Matching in the current study is defined as an exact age and sex match of cases and controls, such that two controls were exactly matched in age and sex with one case. Individual pair matching was used.

Disclosure Status: If there is anyone else who knows the HIV status of the patient it is defined as disclosed.

User: Any level of alcohol use, smoking, Khat use, and Shisha use were operationalized as a user.

Functional status: It is the condition of the patient at the time of enrollment in ART clinic categorized as to whether working (able to perform usual work), ambulatory (able to perform the activity of daily living), or bedridden functional status (not able to perform the activity of daily living).

Isoniazid preventive treatment completion: Taking the complete prophylaxis, such that a dose of $300 \mathrm{mg} /$ day isoniazid for six months.

\section{Data Management and Quality Control}

Data were collected by trained data collectors who had previous experience of data collection in a health-care setting. The data extraction form was pre-tested on the five percent of the sample size and updated accordingly. All patients included in the previous study who developed TB after ART initiation were included in the cases list, and people living with HIV exactly matched in age and sex with cases who did not develop TB during their ART follow-up period were included in the controls list. Among all patients with TB co-infection, those with a pair-matched with controls were selected in the final as cases. Controls were selected systematically using simple random sampling, such that among the available list of controls, two controls for each case were selected systematically.

\section{Data Processing and Analysis}

We exported the data entered into Epi Info 7 to IBM SPSS Statistics version 20 for statistical analysis. Descriptive summary measures were used to characterize demographic, behavioral, and baseline clinical characteristics of study participants. Conditional logistic regression analysis was performed to identify determinants of tuberculosis infection among people living with HIV during their ART follow-up. The bi-variable analysis was performed and those variables with a $P$-value $<0.25$ in the bi-variable analysis were entered into the multivariable analysis to identify the independent determinants. The odds ratio and their $95 \% \mathrm{CI}$ were determined, and those with $a P$-value $<0.05$ were considered as a statistically significant association.

\section{Ethical Considerations}

Ethical clearance was obtained from St. Paul's Hospital Millennium Medical College, Addis Ababa City Administration Health Bureau, and St. Peter Specialized Hospital. A letter of permission was sent to all participating facilities and permission was obtained from these facilities. The study was conducted as per the Declaration of Helsinki. Confidentiality was maintained by using unique identification codes rather than patient names and identifications. A unique study identification number was used in the entire process rather than patient identifiers.

\section{Results}

\section{Demographic and Behavioral Characteristics}

Among 566 people living with HIV enrolled and included in the final analysis of our previous retrospective cohort study, 476 individuals were taking ART during their follow-up period. Of those who were taking the ART drugs, 61 developed TB in their follow-up period and the remaining 415 were not co-infected with TB by the end of the study period. For the current study, we got two exact age and sex matches or controls for each 57 HIV-TB co-infected individuals who were taking ART. However, for the remaining four cases, we did not get exact matches with controls. Thus, we compared 
those 57 cases with 114 controls to assess the determinants of tuberculosis infection while taking ART (Figure 1).

The comparably higher proportion of study participants from both the cases $(20,35.1 \%)$ and the control group (52, $45.6 \%)$ is married. Regarding the educational status, more than half of the cases $(30,53.1 \%)$ and a half from the controls $(57,50 \%)$ either not have formal education or were at the primary level. Likewise, $61.1 \%$ (35) of the cases and $57.0 \%$ (65) of the controls did not have work. About 77.9\% (33) among the cases and 81.6\% (93) had 1-3 family members. Besides, less than half percent of both among the cases and the controls were using tobacco, alcohol, soft drugs like Khat, and hard drugs like Shisha (Table 1).

\section{Clinical Characteristics of Study Participants}

Nearly a quarter $(24.6 \%, 14)$ of the cases were either on ambulatory or bedridden functional status during enrollment; however, this happens for about eight percent of the controls $(7.9 \%, 9) .84 .2 \%$ (48) among the cases and $97.4 \%$ (111) of the controls were categorized under either WHO clinical stage I or II. The majority among the cases $(68.4 \%$, 39) had a baseline CD 4 count $<200$ cells $/ \mu \mathrm{L}$, while the majority of the controls $(60.5 \%, 69)$ had a baseline CD4 count $>200$ cells $/ \mu \mathrm{L}$. Besides, $19.3 \%$ (11) of the cases and
$6.1 \%$ (7) of the controls were anemic at the time of enrollment. Likewise, $42.1 \%$ (24) of the cases and 27.2\% (31) of the controls were undernourished at the baseline. About $21.1 \%$ (12) of the cases had a history of previous TB infection, while this is true for $3.5 \%$ (4) of the controls. About $15.8 \%$ (9) of the cases $36.8 \%$ (42) of the controls took the complete isoniazid preventive treatment. In the end, more than half of the cases $(52.6 \%, 30)$ cases took ART less than a year before they develop TB; however, 71.1\% (81) of the controls took the ART for more than 36 months (Table 2).

The median CD4 count among the cases and the controls were 145.00 (IQR, 80-245) and 224.50 (IQR, 123.75-288.00), respectively. The median $\mathrm{Hgb}$ value among the cases and the controls were 12.4 (IQR, 10.513.95) and 13.85 (IQR $=12.70-15.00)$, respectively. The median length of stay on ART was 8.57 (2.89-34.97) and 53.67 (33.00-60.36) months, respectively (Table 3).

\section{Association of Clinical and Behavioral Factors with Tuberculosis Infection}

Among all the variables assessed in the current study, statistically, significant differences were observed among cases and controls based on previous TB history $(P<0.001)$, baseline functional status $(P=0.010)$, baseline WHO clinical stage $(P=0.001)$, baseline Hgb value

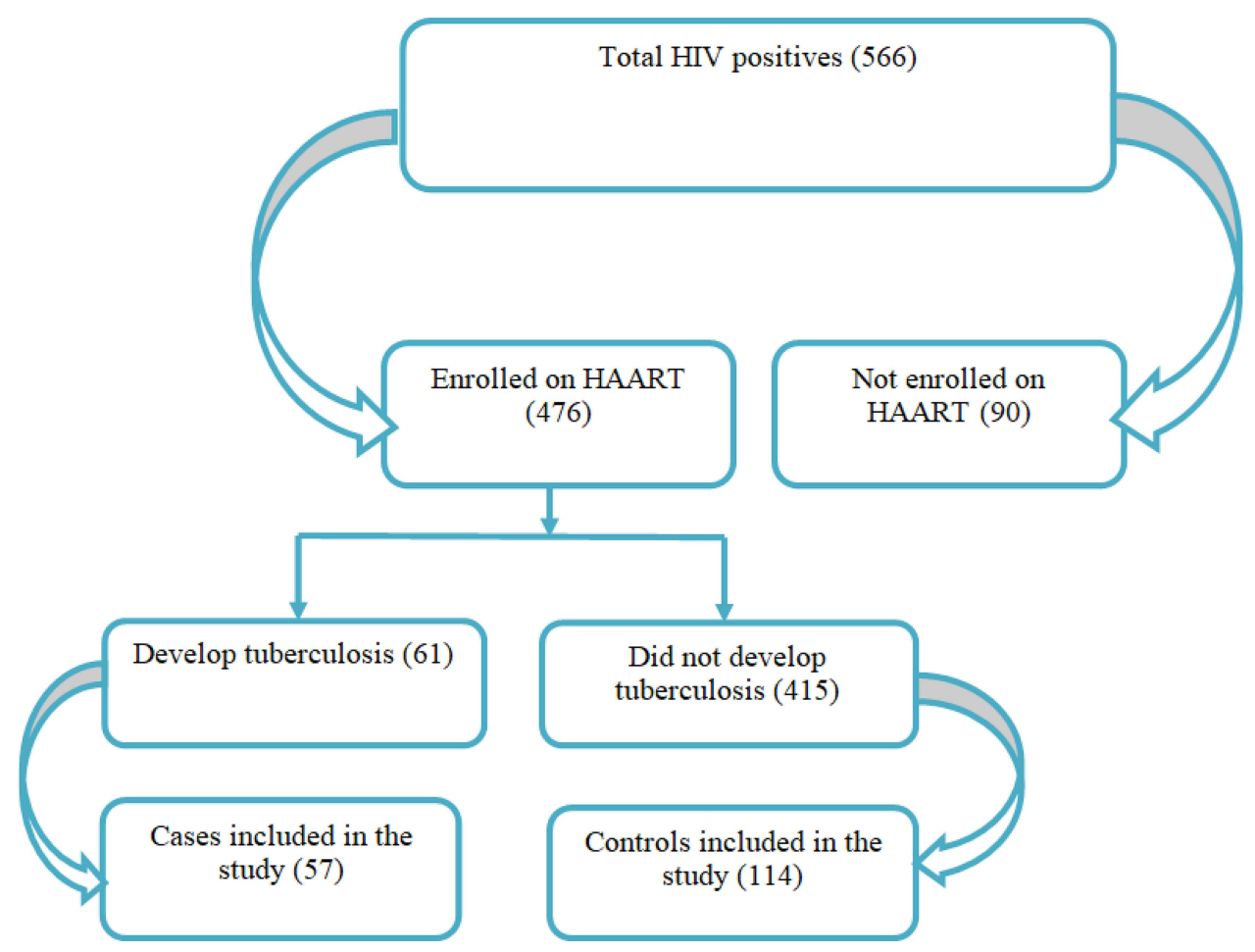

Figure I Flowchart, followed assess the effect of long-term HAART on the incidence of TB among PLWHIV in Addis Ababa, Ethiopia. 
Table I Demographic and Behavioral Characteristics of Study Participants $(n=171)$

\begin{tabular}{|c|c|c|c|c|}
\hline Characteristics & Cases, n (\%) & Controls, n (\%) & $\mathbf{x}^{2}$ & P-value \\
\hline Marital status & & & 3.751 & 0.290 \\
\hline Single & $16(28.1)$ & $31(27.2)$ & & \\
\hline Married & $20(35.1)$ & $52(45.6)$ & & \\
\hline Separated/Divorced & $15(26.3)$ & $17(14.9)$ & & \\
\hline Widowed & $6(10.5)$ & $14(12.3)$ & & \\
\hline Educational status & & & 1.003 & 0.801 \\
\hline No formal education & $10(17.5)$ & $17(14.9)$ & & \\
\hline Primary & $20(35.1)$ & $40(35.1)$ & & \\
\hline Secondary & $20(35.1)$ & $47(4 \mid .2)$ & & \\
\hline Tertiary & $7(12.3)$ & $10(8.8)$ & & \\
\hline Employment status & & & 0.301 & 0.583 \\
\hline Yes & $22(38.6)$ & $49(43.0)$ & & \\
\hline No & $35(61.4)$ & $65(57.0)$ & & \\
\hline Address & & & 0.034 & 0.853 \\
\hline Addis Ababa & $52(91.2)$ & $103(90.4)$ & & \\
\hline Out of Addis Ababa & $5(88)$ & II (9.6) & & \\
\hline Disclosure status & & & 1.425 & 0.233 \\
\hline Yes & $42(73.7 \mathrm{I})$ & $93(81.6)$ & & \\
\hline No & $15(26.3)$ & $2 \mid(18,4$ & & \\
\hline Family size & & & 0.109 & 0.947 \\
\hline $\mathrm{I}-3$ & $33(77.9)$ & $69(60.5)$ & & \\
\hline $4-5$ & $16(28.1)$ & $30(26.3)$ & & \\
\hline$>5$ & $8(\mid 4.0)$ & $15(13.2)$ & & \\
\hline Homeless & & & 0.503 & 0.478 \\
\hline Yes & $0(0.0)$ & I $(0.9)$ & & \\
\hline No & $57(100.0)$ & $113(99.1)$ & & \\
\hline Tobacco smoking & & & $0.77 I$ & 0.380 \\
\hline Yes & $21(36.8)$ & $50(43.9)$ & & \\
\hline No & $36(63.2)$ & $64(56.1)$ & & \\
\hline Alcohol & & & 0.047 & 0.828 \\
\hline Yes & $25(43.9)$ & $52(45.6)$ & & \\
\hline No & $32(56.1)$ & $62(54.4)$ & & \\
\hline Taking Khat & & & 0.048 & 0.827 \\
\hline Yes & $24(42.1)$ & $50(43.9)$ & & \\
\hline No & $33(57.9)$ & $64(56.1)$ & & \\
\hline Taking hard drugs/Shisha & & & 1.249 & 0.264 \\
\hline Yes & $18(31.6)$ & $46(40.4)$ & & \\
\hline No & $39(68.4)$ & $68(59.6)$ & & \\
\hline
\end{tabular}

( $P=0.008)$, baseline BMI $(P=0.049)$, IPT intake $(P=0.005)$, baseline CD4 value $(P<0.001)$ and duration of taking ART $(P<0.001)$ (Table 2).

\section{Determinants of Tuberculosis Infection} Bi-Variable Analysis

In the bi-variable analysis eight variables; previous tuberculosis infection history, baseline functional status, baseline WHO clinical stage, baseline Hgb value, baseline BMI, IPT intake, baseline CD4 value, and months of ART intake give a P-value $<0.25$. Based on the crude data, all these variables except baseline BMI had a statistically significant association with TB infection among people living with HIV who were taking ART. The crude odds ratio and the confidence interval for the variables is as follows: previous tuberculosis infection history (cOR; 2.744, 95\% CI;1.454-5.180), baseline functional status (ambulatory, cOR; 3.243, 95\% CI;1.269-8.288, bedridden, cOR; 4.00, 95\% CI; 0.363-44.133), baseline WHO clinical stage (cOR; 8.293, 95\% CI;1.77-38.693), baseline Hgb value (cOR; 1.857, 95\% CI;1.125-3.064), 
Table 2 Baseline Clinical Characteristics of Study Participants $(n=171)$

\begin{tabular}{|c|c|c|c|c|}
\hline Characteristics & Cases, n (\%) & Controls, n (\%) & $x^{2}$ & P-value \\
\hline Previous TB history & & & 13.790 & $<0.001$ \\
\hline Yes & $12(2 \mid . I)$ & $4(3.5)$ & & \\
\hline No & $45(78.9)$ & $110(96.5)$ & & \\
\hline Baseline functional status & & & 9.120 & 0.010 \\
\hline Working & $43(75.4)$ & $105(92.1)$ & & \\
\hline Ambulatory & $12(2 \mid .1)$ & $8(7.0)$ & & \\
\hline Bedridden & $2(3.5)$ & I (0.9) & & \\
\hline Baseline WHO stage & & & 10.083 & 0.001 \\
\hline $\mathrm{I} / \mathrm{II}$ & $48(84.2$ & III (97.4) & & \\
\hline III/ IV & $9(15.8)$ & $3(2.6)$ & & \\
\hline Baseline Hgb & & & 6.985 & 0.008 \\
\hline$<10 \mathrm{~g} / \mathrm{dl}$ & II (19.3) & $7(6.1)$ & & \\
\hline$>10 \mathrm{~g} / \mathrm{dl}$ & $46(80.7)$ & $107(93.9)$ & & \\
\hline BMI & & & 3.873 & 0.049 \\
\hline$<18.5$ & $24(42.1)$ & $31(27.2)$ & & \\
\hline$>18.5$ & $33(57.9)$ & $83(72.8)$ & & \\
\hline Initial treatment & & & 4.309 & 0.230 \\
\hline TDF/3TC/NVP & $8(14.0)$ & $17(14.9)$ & & \\
\hline $\mathrm{AZT} / 3 \mathrm{TC} / \mathrm{NVP}$ & $0(0.0)$ & 5 (4.4.) & & \\
\hline AZT/3TC/EFV & $45(78.9)$ & $89(78.1)$ & & \\
\hline TDF/3TC/EFV & $4(7.0)$ & $3(2.6)$ & & \\
\hline Took IPT Prophylaxis & & & 8.047 & 0.005 \\
\hline Yes & $9(15.8)$ & $42(36.8)$ & & \\
\hline No & $48(84.2)$ & $72(63.2$ & & \\
\hline Co-infection & & & 0.299 & 0.585 \\
\hline Yes & $26(45.6)$ & $47(4 \mid .2)$ & & \\
\hline No & $31(54.4)$ & $67(58.8$ & & \\
\hline CD4 & & & $|2.74|$ & $<0.001$ \\
\hline$<200$ & $39(68.4)$ & $45(39.5)$ & & \\
\hline$>200$ & $18(31.6)$ & $69(60.5$ & & \\
\hline Months ART has taken & & & 53.359 & $<0.001$ \\
\hline$<12$ Months & $30(52.6)$ & $8(7.0)$ & & \\
\hline 13-36 Months & $15(26.3)$ & $25(21.9)$ & & \\
\hline$>36$ Months & $12(2||)$. & $8171.1)$ & & \\
\hline
\end{tabular}

Abbreviations: ART, anti-retroviral treatment; BMI, body mass index; Hgb, hemoglobin; TB, tuberculosis; co-infection, infection with one or more infections other than TB; WHO, World Health Organization; IPT, isoniazid preventive treatment.

IPT intake (cOR; 3.415, 95\% CI; 1.437-8.118), baseline CD4 value (cOR; 1.796, 95\% CI; 1.273-2.54) and months of ART intake (<12 Months, cOR; 28.391, 95\% CI;7.705104.6, 13-36 Months, cOR; 3.876, 95\% CI; 1.416-10.609) (Table 4).

\section{Multi-Variable Analysis}

Based on the multivariable conditional logistic regression model, among all variables, a statistically significant association was found between length of stay in ART and tuberculosis infection. Accordingly, people living with HIV who were taking anti-retroviral drugs less than 12 months had about six times the odds to develop tuberculosis infection compared to those taking ART drugs for more than 36 months $(\mathrm{aOR}=5.925,95 \% \mathrm{CI}=2.649$ 13.250) (Table 4).

\section{Discussion}

In this study, we assessed the demographic, behavioral, and baseline clinical determinants of tuberculosis infection among people living with HIV during their ART followup. From our previous retrospective cohort study, we performed a matched nested case-control study where the cases and controls were pair-matched exactly in age and 
Table 3 Baseline CD4 and Hemoglobin, and Duration of ART Among Cases $(n=57)$ and Controls $(n=114)$

\begin{tabular}{|l|l|l|l|}
\hline Variable & Group & Median (Range) & Interquartile Range \\
\hline \multirow{2}{*}{ CD4 value } & Cases & $145.00(15-101 \mathrm{I}) \mathrm{cells} / \mu \mathrm{L}$ & $80-245 \mathrm{cells} / \mu \mathrm{L}$ \\
\cline { 2 - 4 } & Controls & $224.50(8-870) \mathrm{cell} / \mathrm{sL}$ & $123.75-288.00 \mathrm{cells} / \mu \mathrm{L}$ \\
\hline \multirow{2}{*}{ Hemoglobin value } & Cases & $12.4(6.00-17.70) \mathrm{g} / \mathrm{dl}$ & $10.5-13.95 \mathrm{~g} / \mathrm{dl}$ \\
\cline { 2 - 4 } & Controls & $13.85(8.60-20.90) \mathrm{g} / \mathrm{dl}$ & $12.70-15.00 \mathrm{~g} / \mathrm{dl}$ \\
\hline \multirow{2}{*}{$\begin{array}{l}\text { ART duration in } \\
\text { months }\end{array}$} & Cases & $8.57(0-61)$ & $2.89-34.97$ \\
\cline { 2 - 4 } & Controls & $53.67(2-61)$ & $33.00-60.36$ \\
\hline \multirow{2}{*}{$\begin{array}{l}\text { ART duration in } \\
\text { days }\end{array}$} & Cases & $263.50(5-1825)$ & $86.25-1057.50$ \\
\cline { 2 - 4 } & Controls & $1610.00(54-1825)$ & $1137.50-1810.75$ \\
\hline
\end{tabular}

Abbreviation: ART, anti-retroviral treatment.

Table 4 Determinants of Tuberculosis Infection Among People Living with HIV After ART Initiation $(n=17 I)$

\begin{tabular}{|c|c|c|c|c|}
\hline Characteristics & Cases, n (\%) & Controls, n (\%) & cOR & aOR \\
\hline \multicolumn{5}{|c|}{ Previous TB history } \\
\hline Yes & $12(21.1)$ & $4(3.5)$ & $2.744(1.454-5.180)$ & $4.86 \mid(0.882-26.788)$ \\
\hline No & $45(78.9)$ & $110(96.5)$ & 1.00 & 1.00 \\
\hline \multicolumn{5}{|c|}{ Baseline functional status } \\
\hline Working & $43(75.4)$ & $105(92.1)$ & 1.00 & 1.00 \\
\hline Ambulatory & $12(2 \mid .1)$ & $8(7.0)$ & $3.243(1.269-8.288)$ & $0.963(0.163-5.692)$ \\
\hline Bedridden & $2(3.5)$ & I (0.9) & $4.00(0.363-44.133)$ & $0.772(0.026-22.915)$ \\
\hline \multicolumn{5}{|c|}{ Baseline WHO stage } \\
\hline $\mathrm{I} / \mathrm{II}$ & $48(84.2$ & III (97.4) & 1.00 & 1.00 \\
\hline III/ IV & $9(15.8)$ & $3(2.6)$ & $8.293(1.77-38.693)$ & $1.747(0.198-15.415)$ \\
\hline \multicolumn{5}{|l|}{ Baseline Hgb } \\
\hline$<\log / \mathrm{dl}$ & II (19.3) & $7(6.1)$ & $1.857(1.125-3.064)$ & $0.68 I(0.13|-3.53|)$ \\
\hline$>10 \mathrm{~g} / \mathrm{dl}$ & $46(80.7)$ & $107(93.9)$ & 1.00 & 1.00 \\
\hline \multicolumn{5}{|l|}{ BMI } \\
\hline$<18.5$ & $24(42.1)$ & $31(27.2)$ & $1.414(0.998-2.004)$ & $1.915(0.678-5.411)$ \\
\hline$>18.5$ & $33(57.9)$ & $83(72.8)$ & 1.00 & $\mathrm{I}: 00$ \\
\hline \multicolumn{5}{|c|}{ Took IPT Prophylaxis } \\
\hline Yes & $9(15.8)$ & $42(36.8)$ & 1.00 & 1.00 \\
\hline No & $48(84.2)$ & $72(63.2$ & $3.415(1.437-8.118)$ & $1.340(0.404-4.448)$ \\
\hline \multicolumn{5}{|l|}{ CD4 } \\
\hline$<200$ & $39(68.4)$ & $45(39.5)$ & $1.796(1.273-2.54)$ & $2.358(0.948-5.865)$ \\
\hline$>200$ & $18(31.6)$ & $69(60.5$ & 1.00 & 1.00 \\
\hline \multicolumn{5}{|c|}{ Months ART has taken } \\
\hline$<12$ Months & $30(52.6)$ & $8(7.0)$ & 28.391 (7.705-104.6I2) & $5.925(2.649-13.250)$ \\
\hline 13-36 Months & I5 (26.3) & $25(21.9)$ & $3.876(1.416-10.609)$ & $0.809(0.423-1.545)$ \\
\hline$>36$ Months & $12(21.1)$ & $8171.1)$ & 1.00 & 1.00 \\
\hline
\end{tabular}

Abbreviations: ART, anti-retroviral treatment; BMI, body mass index; Hgb, hemoglobin; TB, tuberculosis; WHO, World Health Organization; IPT, isoniazid preventive treatment.

sex. The main objective was to assess the effect of longterm ART on the incidence of tuberculosis among people living with HIV. Accordingly, the finding supports our hypothesis, such that long-term exposure to ART significantly decreases the incidence of TB among people living with HIV during their follow-up.
In our previous retrospective study, ${ }^{13}$ we were able to assess and compare the incidence of tuberculosis infection among people living with HIV who were taking ART with those who did not take ART. The findings showed that taking ART significantly decreases the incidence of tuberculosis. ${ }^{10}$ However, still, a considerable proportion 
$(12.8 \%, 61)$ of people living with HIV was infected with TB after ART initiation.

Based on the chi-squared test, TB co-infection among people living with HIV after HAART initiation was associated with previous TB history, baseline functional status, baseline WHO clinical stage, baseline Hgb value, baseline BMI, IPT intake, baseline CD4 value, and duration of taking ART. In support of the present study finding, the association of TB infection with previous TB infection history was reported previously. ${ }^{25,26}$ The recurrence of TB among the previously treated people living with HIV might be due to the reinfection in a high TB setting like the current study setting. ${ }^{27}$ Being on the advanced clinical stages such as WHO stage III/IV, lower CD4 count $(<200$ cells $/ \mu \mathrm{L}$ ), undernutrition (BMI $<18.5 \mathrm{Kg} / \mathrm{m}^{2}$ ), and bedridden functional status at the time of ART enrollment to ART was repeatedly reported to be associated with TB infection among people living with HIV. ${ }^{10,16,28-30}$ The advanced clinical stages might be occurred due to the late diagnosis or late healthcare-seeking behavior of study participants. ${ }^{31,32}$ These advanced clinical stages at the baseline might lead people living with HIV susceptible to subsequent infections including tuberculosis. When the WHO AIDS clinical staging becomes more advanced, the risk of developing and recurrence TB simultaneously increased. More importantly, those individuals with lower CD4 cell counts had higher viral load count, and that ultimately suppressed the immune system resulting in the occurrence of TB. Also, those people living with HIV having a bedridden functional status had an advanced disease stage and become more immune-compromised resulting in higher TB risk. In addition, this study indicated an association between lower Hgb value and TB. The low level of Hgb indicated the level of immune compromisation. Besides, the finding revealed that there is an association between lower BMI and TB in individuals living with HIV. Undernutrition lowers immunity that results in increasing the risk of TB reactivation.

The other associated factor with $\mathrm{TB}$ in the current study is IPT intake status. As reported in previous studies, not taking the complete IPT prophylaxis is a risk factor for TB infection in people living with HIV. ${ }^{16,29,30,33}$ WHO recommends people living with HIV take a complete dose of IPT, such that a dose of $300 \mathrm{mg}$ isoniazid per day for six months. ${ }^{34}$

The finding of the present study revealed that those people living with HIV who took ART for less than 12 months had about six times the odds to be infected with
TB compared to those taken for more than 36 months. In support of this, a previous study reported that long-term exposure to ART decreased the odds of tuberculosis infection in people living with $\mathrm{HIV}^{35}$ and the reverse is true. Likewise, a higher incidence of TB in the early phase of HAART initiation is reported previously in a different setting. ${ }^{36}$ This higher TB incidence in this stage might have several explanations. First, the advanced clinical stages such as low level of CD4 count at the time of ART initiation might be one factor. Secondly, TB-associated immuneinflammatory immune response (IRIS) might be the other factor. ${ }^{37}$ To the end, this study has important limitations, including the small sample size and the nature of the retrospective data as it was extracted from patient registries. Also, the incomplete records were excluded due to the absence of baseline data in the original retrospective cohort study, where we selected cases and controls that might introduce selection bias. In addition, an exact match in age and sex might not be enough since there are many determinants of TB infection in people living with HIV. Further, the absence of data on latent TB status at the bases line is another limitation. Besides, this study might have a limitation since the study is based in a low-income country with limitations in screening TB in people living with HIV throughout their ART follow-up.

\section{Conclusion}

A considerable proportion of individuals were infected with tuberculosis after the initiation of HAART. Baseline immunological and clinical profiles such as WHO stage III/IV, anemia, undernutrition, lower CD4 count and bedridden and ambulatory functional status, previous TB history, and not taking IPT were associated with TB infection. Most of the TB cases occurred among patients who were taking ART for less than a year and the independent determinant of TB infection was the length of stay on HAART. However, the long duration of ART exposure significantly decreases tuberculosis incidence. Thus, retaining people living with HIV on ART would be important to decrease the incidence of TB in this group of individuals.

\section{Abbreviations}

ART, Antiretroviral Therapy; BMI, Body Mass Index; Hgb, Hemoglobin; HAART, Highly Active Antiretroviral Therapy; HIV, Human Immunodeficiency Virus; IPT, Isoniazid Preventive Treatment; MDR-TB, Multi Drug Resistant; PLWHIV, People living with Human 
Immunodeficiency Virus; TB, Tuberculosis; WHO, World Health Organization.

\section{Data Sharing Statement}

The data is available upon request with the corresponding author.

\section{Ethics Approval and Consent to Participate}

The study obtained ethical clearance from St. Paul's Hospital Millennium Medical College, Addis Ababa City Administration Health Bureau, and St. Peter Specialized Hospital. Since it is a study based on a review of patient registries, consent was not applicable. Besides, any patient identifier was not used in the entire process to keep confidentiality.

\section{Acknowledgments}

We would like to thank St. Paul's Hospital Millennium Medical College, Addis Ababa City Administration Health Bureau, and St. Peter Specialized Hospital for their permission to conduct the study. Our gratitude goes to the staff of each health facility and the data collectors.

\section{Author Contributions}

All authors made a significant contribution to the work reported, whether that is in the conception, study design, execution, acquisition of data, analysis and interpretation, or in all these areas; took part in drafting, revising or critically reviewing the article; gave final approval of the version to be published; have agreed on the journal to which the article has been submitted; and agree to be accountable for all aspects of the work.

\section{Funding}

This research did not receive any specific grant from funding agencies in the public, commercial, or not-forprofit sectors.

\section{Disclosure}

The authors have declared that no competing interests exist in this work.

\section{References}

1. Kwan CK, Ernst JD. HIV and tuberculosis: a deadly human syndemic. Clin Microbiol Rev. 2011;24(2):351-376. doi:10.1128/CMR.00042-10
2. Meda ZC, Sombie I, Sanon OW, Mare D, Morisky DE, Chen YM. Risk factors of tuberculosis infection among HIV/AIDS patients in Burkina Faso. AIDS Res Hum Retroviruses. 2013;29(7):1045-1055. doi:10.1089/aid.2012.0239

3. World Health Organization. WHO Policy on Collaborative TB/HIV Activities, Guidelines for National Programs, and Other Stakeholders. Geneva, Switzerland: World Health Organization; 2012.

4. World Health Organization. TB/HIV, HIV-Associated Tuberculosis Fact Sheet. Geneva, Switzerland: World Health Organization; 2018.

5. World Health Organization. Global Tuberculosis Report. Geneva, Switzerland: World Health Organization; 2021.

6. World Health Organization. Global Tuberculosis Report. Geneva, Switzerland: World Health Organization; 2020.

7. Alene KA, Viney K, Moore HC, Wagaw M, Clements ACA. Spatial patterns of tuberculosis and HIV co-infection in Ethiopia. PLoS One. 2019;14(12):e0226127. doi:10.1371/journal.pone.0226127

8. Alemu YM, Awoke W, Wilder-Smith A. Determinants for tuberculosis in HIV-infected adults in Northwest Ethiopia: a multicentre case-control study. BMJ Open. 2016;6(4):e009058. doi:10.1136/ bmjopen-2015-009058

9. Badri M, Wilson D, Wood R. Effect of highly active antiretroviral therapy on incidence of tuberculosis in South Africa: a cohort study. Lancet. 2002;359(9323):2059-2064. doi:10.1016/S0140-6736(02)08904-3

10. Cui Z, Lin M, Nie S, Lan R. Risk factors associated with Tuberculosis (TB) among people living with HIV/AIDS: a pair-matched case-control study in Guangxi, China. PLoS One. 2017;12(3):e0173976. doi:10.1371/journal.pone.0173976

11. Miranda A, Morgan M, Jamal L, et al. Impact of antiretroviral therapy on the incidence of tuberculosis: the Brazilian experience, 1995-2001. PLoS One. 2007;2(9):e826. doi:10.1371/journal. pone. 0000826

12. Del Amo J, Moreno S, Bucher HC, et al. Impact of antiretroviral therapy on tuberculosis incidence among HIV-positive patients in high-income countries. Clin Infect Dis. 2012;54(9):1364-1372.

13. Alemu A, Yesuf A, Zerihun B, Getu M, Worku T, Bitew ZW. Incidence and determinants of tuberculosis among HIV-positive individuals in Addis Ababa, Ethiopia: a retrospective cohort study. Int $J$ Infect Dis. 2020;95:59-66. doi:10.1016/j.ijid.2020.02.053

14. Taha M, Deribew A, Tessema F, Assegid S, Duchateau L, Colebunders R. Risk factors of active tuberculosis in people living with HIV/AIDS in southwest Ethiopia: a case-control study. Ethiop $J$ Health Science. 2011;21(2):131-140.

15. Yirdaw KD, Teklu AM, Mamuye AT, Zewdu S. Breakthrough tuberculosis disease among people with HIV - should we be worried? A retrospective longitudinal study. PLoS One. 2019;14(2): e0211688. doi:10.1371/journal.pone.0211688

16. Kibret KT, Yalew AW, Belaineh BG, Asres MM. Determinant factors associated with occurrence of tuberculosis among adult people living with HIV after antiretroviral treatment initiation in Addis Ababa, Ethiopia: a case-control study. PLoS One. 2013;8(5):e64488. doi:10.1371/journal.pone. 0064488

17. Azanaw MM, Derseh NM, Yetemegn GS, Angaw DA. Incidence and predictors of tuberculosis among HIV patients after initiation of ART treatment in Ethiopia: a systematic review and meta-analysis. Res $S q$. 2020. doi:10.21203/rs.2.19054/v1

18. Mitku AA, Dessie ZG, Muluneh EK, Workie DL. Prevalence and associated factors of TB/HIV co-infection among HIV infected patients in Amhara region, Ethiopia. Afr Health Sci. 2016;16 (2):588-595. doi:10.4314/ahs.v16i2.29

19. Aemro A, Jember A, Anlay DZ. Incidence and predictors of tuberculosis occurrence among adults on antiretroviral therapy at Debre Markos referral hospital, Northwest Ethiopia: a retrospective follow-up study. BMC Infect Dis. 2020;20(1):245. doi:10.1186/ s12879-020-04959-y 
20. Girardi E, Sabin CA, Monforte AA, et al. Incidence of tuberculosis among HIV-infected patients receiving highly active antiretroviral therapy in Europe and North America. Clin Infect Dis. 2005;41:1772-1782.

21. Alene KA, Nega A, Taye BW. Incidence and predictors of tuberculosis among adult people living with human immunodeficiency virus at the University of Gondar Referral Hospital, Northwest Ethiopia. BMC Infect Dis. 2013;13(1):292. doi:10.1186/1471-2334-13-292

22. Kassa A, Teka A, Shewaamare A, Jerene D. Incidence of tuberculosis and early mortality in a large cohort of HIV infected patients receiving antiretroviral therapy in a tertiary hospital in Addis Ababa, Ethiopia. Trans $R$ Soc Trop Med Hyg. 2012;106(6):363-370. doi:10.1016/j.trstmh.2012.03.002

23. Ahmed A, Mekonnen D, Shiferaw AM, Belayneh F, Yenit MK. Incidence and determinants of tuberculosis infection among adult patients with HIV attending HIV care in north-east Ethiopia: a retrospective cohort study. BMJ Open. 2018;8(2):e016961. doi:10.1136/bmjopen-2017-016961

24. Federal Democratic Republic of Ethiopia Ministry of Health. National comprehensive tuberculosis, leprosy and TB/HIV training manual for health care workers; 2016:26.

25. Seyler C, Toure S, Messou E, Bonard D, Gabillard D, Anglaret X. Risk factors for active tuberculosis after antiretroviral treatment initiation in Abidjan. Am J Respir Crit Care Med. 2005;172 (1):123-127. doi:10.1164/rccm.200410-1342OC

26. Nugus GG, Irena ME. Determinants of active tuberculosis occurrences after ART initiation among adult HIV-positive clients in West Showa Zone Public Hospitals, Ethiopia: a case-control study. Adv Public Health. 2020;2020:1-8. doi:10.1155/2020/8237928

27. Unis G, Ribeiro AW, Esteves LS, et al. Tuberculosis recurrence in a high incidence setting for HIV and tuberculosis in Brazil. BMC Infect Dis. 2014;14(1):548. doi:10.1186/s12879-014-0548-6

28. Brinkhof MWG, Egger E, Boulle A, et al. Tuberculosis after initiation of antiretroviral therapy in low-income and high-income countries. Clin Infect Dis. 2007;45(11):1518-1521.

29. Tiruneh G, Getahun A, Adeba E. Assessing the Impact of Isoniazid Preventive Therapy (IPT) on tuberculosis incidence and predictors of tuberculosis among adult patients enrolled on ART in Nekemte Town, Western Ethiopia: a retrospective cohort study. Interdiscip Perspect Infect Dis. 2019;2019:1413427. doi:10.1155/2019/1413427
30. Gunda DW, Maganga SC, Nkandala I, et al. Prevalence and risk factors of active TB among adult HIV patients receiving ART in Northwestern Tanzania: a retrospective cohort study. Can J Infect Dis Med Microbiol. 2018;2018:1346104. doi:10.1155/2018/1346104

31. Kigozi IM, Dobkin LM, Martin JN, et al. Late-disease stage at presentation to an HIV clinic in the era of free antiretroviral therapy in Sub-Saharan Africa. J Acquir Immune Defic Syndr. 2009;52 (2):280-289. doi:10.1097/QAI.0b013e3181ab6eab

32. Hu X, Liang B, Zhou C, et al. HIV late presentation and advanced HIV disease among patients with newly diagnosed HIV/AIDS in Southwestern China: a large-scale cross-sectional study. AIDS Res Ther. 2019;16(1):6. doi:10.1186/s12981-019-0221-7

33. Dravid A, Natarajan K, Medisetty M, et al. Incidence of tuberculosis among HIV infected individuals on long term antiretroviral therapy in private healthcare sector in Pune, Western India. BMC Infect Dis. 2019;19(1):714. doi:10.1186/s12879-019-4361-0

34. World Health Organization. Implementing the WHO Stop TB Strategy. Geneva, Switzerland: World Health Organization; 2008.

35. Pettit AC, Jenkins CA, Stinnette SE, et al. Tuberculosis risk before and after highly active antiretroviral therapy initiation: does HAART increase the short-term TB risk in a low incidence TB setting? J Acquir Immune Defic Syndr. 2011;57(4):305-310. doi:10.1097/ QAI.0b013e3182182e2d

36. Van Rie A, Westreich D, Sanne I. Tuberculosis in patients receiving antiretroviral treatment: incidence, risk factors, and prevention strategies. J Acquir Immune Defic Syndr. 2011;56(4):349-355. doi:10.1097/QAI.0b013e3181f9fb39

37. Ali K, Klotz SA. The immune reconstitution inflammatory syndrome with tuberculosis: a common problem in Ethiopian HIV-infected patients beginning antiretroviral therapy. J Int Assoc Physicians AIDS Care. 2012;11(3):198-202. doi:10.1177/1545109711402212
Infection and Drug Resistance

\section{Publish your work in this journal}

Infection and Drug Resistance is an international, peer-reviewed openaccess journal that focuses on the optimal treatment of infection (bacterial, fungal and viral) and the development and institution of preventive strategies to minimize the development and spread of resistance. The journal is specifically concerned with the epidemiology of

\section{Dovepress}

antibiotic resistance and the mechanisms of resistance development and diffusion in both hospitals and the community. The manuscript management system is completely online and includes a very quick and fair peerreview system, which is all easy to use. Visit http://www.dovepress.com/ testimonials.php to read real quotes from published authors. 